\title{
Long-term MRI tracking of dual-labeled adipose- derived stem cells homing into mouse carotid artery injury
}

This article was published in the following Dove Press journal:

International Journal of Nanomedicine

I October 2012

Number of times this article has been viewed

\author{
Jin-Bao Qin 1,5,* \\ Kang-An Li ${ }^{2, *}$ \\ Xiang-Xiang $\mathrm{Li}^{1,5}$ \\ Qing-Song $\mathrm{Xie}^{3}$ \\ Jia-Ying Lin $^{4}$ \\ Kai-Chuang Ye $\mathrm{Ye}^{1,5}$ \\ Mi-Er Jiang ${ }^{1,5}$ \\ Gui-Xiang Zhang ${ }^{2}$ \\ Xin-Wu Lu', ${ }^{1,5}$ \\ 'Department of Vascular Surgery, \\ Shanghai Ninth People's Hospital \\ Affiliated to Shanghai Jiao Tong \\ University, School of Medicine, \\ ${ }^{2}$ Department of Radiology, Shanghai \\ First People's Hospital, Shanghai \\ Jiao Tong University School of \\ Medicine, Shanghai, ' ${ }^{3}$ epartment of \\ Neurosurgery, Cixi Municipal People's \\ Hospital, Zhejiang Province, China; \\ ${ }^{4}$ Clinic for Gynecology, Charite- \\ Universitatsmedizin Berlin, Berlin, \\ Germany; ${ }^{5}$ Vascular Center, Shanghai \\ Jiao Tong University, Shanghai, China
}

*These two authors contributed equally to this work

Correspondence: Xin-Wu Lu

Department of Vascular Surgery, Shanghai Ninth People's Hospital Affiliated to Shanghai Jiao Tong University, School of Medicine, Number 639 Zhi Zao Ju Road,

Shanghai, 2000II, China

Tel +86 2l 63240090

Fax +86 21 63240825

Email luxinwu@yahoo.com.cn

Gui-Xiang Zhang

Department of Radiology, Shanghai First People's Hospital, Shanghai Jiao Tong University School of Medicine,Number 100 Haining Road, Shanghai, 200080, China

Tel +86 2I 63240090 extn 4166

Fax +862163240825

Email guixiangzhang@sina.com
Background: Stem cell therapy has shown great promise for regenerative repair of injured or diseased tissues. Adipose-derived stem cells (ADSCs) have become increasingly attractive candidates for cellular therapy. Magnetic resonance imaging has been proven to be effective in tracking magnetic-labeled cells and evaluating their clinical relevance after cell transplantation. This study investigated the feasibility of imaging green fluorescent protein-expressing ADSCs (GFP-ADSCs) labeled with superparamagnetic iron oxide particles, and tracked them in vivo with noninvasive magnetic resonance imaging after cell transplantation in a model of mouse carotid artery injury.

Methods: GFP-ADSCs were isolated from the adipose tissues of GFP mice and labeled with superparamagnetic iron oxide particles. Intracellular stability, proliferation, and viability of the labeled cells were evaluated in vitro. Next, the cells were transplanted into a mouse carotid artery injury model. Clinical $3 \mathrm{~T}$ magnetic resonance imaging was performed immediately before and 1, 3, 7, 14, 21, and 30 days after cell transplantation. Prussian blue staining and histological analysis were performed 7 and 30 days after transplantation.

Results: GFP-ADSCs were found to be efficiently labeled with superparamagnetic iron oxide particles, with no effect on viability and proliferation. Homing of the labeled cells into the injured carotid artery tissue could be monitored by magnetic resonance imaging.

Conclusion: Magnetically labeled ADSCs with expression of GFP can home into sites of vascular injury, and may provide new insights into understanding of cell-based therapy for cardiovascular lesions.

Keywords: adipose-derived stem cells, carotid artery injury, magnetic resonance imaging, iron oxide particles, cell therapy

\section{Introduction}

Cardiovascular disease, especially atherosclerosis, has become an increasingly serious public health problem in aging countries, resulting in an increased morbidity, mortality, and health care burden. ${ }^{1}$ Atherosclerosis is a diffuse disease, characterized by endothelial injury and lipid accumulation in arterial walls. ${ }^{2}$ During the process of endothelial repair after vascular injury, maintenance of adequate numbers of mature endothelial cells is crucial for preventing thrombosis and intimal hyperplasia. ${ }^{2}$

Stem cell therapy has emerged as one of the most promising treatments for injured endothelium, and has opened up new avenues for preventing intimal hyperplasia. ${ }^{3,4}$ Most researchers in this area have used bone marrow stem cells as seed cells. However, these cells are relatively sparse and cannot be easily expanded with age. ${ }^{5}$ Adipose tissue contains abundant and pluripotent stem cells, which can be easily isolated and 
expanded in vitro. ${ }^{6}$ Adipose-derived stem cells (ADSCs) can differentiate into osteoblasts, neurons, adipocytes, chondrocytes, and myocardial cells. ${ }^{6,7}$ Furthermore, unlike other cell types, ADSCs can be used in an autologous manner without consideration of ethical issues. Therefore, ADSCs have considerable appeal and have become an excellent candidate in regenerative medicine, and may serve as new seed cells for treating vascular lesions in the future.

The major issue in stem cell transplantation is monitoring the migration, distribution, and differentiation of transplanted cells. ${ }^{8}$ Therefore, the ability to track cell migration, cell homing, and cellular fate noninvasively in vivo is important in illustrating the complex roles of transplanted cells in preclinical trials. Magnetic resonance imaging (MRI) has the advantages of high temporal and spatial resolution, and the ability to measure multiple physiologic parameters with different pulse sequences. These advantages are very promising for dynamically tracking cell homing after transplantation in vivo. ${ }^{9}$ Superparamagnetic iron oxide nanoparticles (SPIO) have been used as targeted and molecular probes for many years to improve image contrast in MRI. SPIO can effectively label many cell types, and labeled cells can be monitored for several weeks. ${ }^{10-12}$

Recently, stem cells have been transfected with vectors carrying fluorescent markers, an area which has attracted a growing number of researchers. ${ }^{13,14}$ Green fluorescent protein (GFP) is an excellent transgene marker because it can be easily tracked and identified in cultured living cells in vitro and has already been used in transplantation in vivo. ${ }^{15}$ GFP-expressing transgenic mice are easily obtained in many places, and are an important source of murine ADSCs and bone marrow stem cells continuously expressing GFP.

In this study, GFP-expressing adipose-derived stem cells (GFP-ADSCs) were isolated, expanded, and subsequently labeled with magnetic SPIO nanoparticles. The labeled cells were then transplanted into C57/BL6 mice with acute injury into the left carotid artery. Clinical $3 \mathrm{~T}$ MRI was performed to investigate homing of the transplanted GFP-ADSCs to the injured vascular lesions in live animals.

\section{Materials and methods}

\section{Isolation and expansion of GFP-ADSCs}

Transgenic C57/BL6-GFP mice $(\mathrm{n}=12)$ were obtained from the Model Animal Research Center of Nanjing University. The mice were uniformly green with the exception of hair and red blood cells. ${ }^{16}$ They were sacrificed by decapitation and their bilateral inguinal adipose tissues were aseptically harvested under a dissecting microscope. An enzymatic $\alpha$-MEM solution (Hyclone, Logan, UT), prepared with $0.05 \%(\mathrm{w} / \mathrm{v})$ dispase II (neutral protease, grade II, Roche, Grenzach, Germany) and $0.2 \%(\mathrm{w} / \mathrm{v})$ collagenase NB4 (Serva, Heidelberg, Germany) was added to digest the fat pads, and incubated in a cell incubator (Thermo, Waltham, MA) at $37^{\circ} \mathrm{C}$ for 90 minutes. The mixture was further centrifuged at $600 \times \mathrm{g}$ for 5 minutes. After removing the supernatant, the cell pellet was resuspended in low-glucose Dulbecco's modified Eagle's medium (Hyclone) with $10 \%$ fetal bovine serum and $1 \%$ penicillin-streptomycin. A Trypan blue exclusion assay was carried out to monitor cell viability. The cells were incubated in a cell incubator in a humidified atmosphere of $5 \% \mathrm{CO}_{2}$ at $37^{\circ} \mathrm{C}$. The medium was changed after 2 days, and every 2 days thereafter. When the attached cells reached $80 \%-90 \%$ confluence, the cultures were trypsinized and passaged at 1:2.

\section{Flow cytometric characterization of GFP-ADSCs}

GFP-ADSCs from the third passage expansion were washed with phosphate buffer solution and detached from the culture disc using $0.25 \%$ trypsin-ethylenediamine tetra-acetic acid (Gibco, CA). The cells were incubated with phycoerythrinconjugated anti-mouse antibodies against CD11b, CD31, CD34, CD83, CD90, CD105, and CD133 for 30 minutes at $4^{\circ} \mathrm{C}$ in the dark. Isotype control antibodies were used as the control group (all from eBioscience, San Diego, CA). The cells were washed with phosphate buffer solution and then analyzed using a flow cytometer (Beckman Coulter, Fullerton, CA).The data were analyzed using CXP software (Beckman Coulter).

\section{Multipotent differentiation of GFP-ADSCs}

Following previously established methods,${ }^{17}$ the GFPADSCs from the third passage expansion were cultured in osteogenic, adipogenic, and chondrogenic media to evaluate the multipotent potential of the sorted cells. The cells were cultured in a regular culture medium (Dulbecco's modified Eagle's medium plus $10 \%$ fetal bovine serum ) as a control group. The onset of osteoblast formation was evaluated after 3 weeks by assessing calcium accumulation using Alizarin Red (Sigma-Aldrich, St Louis, MO). Adipogenically differentiated cells were stained with Oil Red-O (SigmaAldrich) followed by microscopic observation to visualize the red-stained oil droplets. After 3 weeks, the chondrocyte pellets were fixed and embedded in paraffin blocks and 
analyzed by collagen II (Abcam, Cambridge, MA) and hematoxylin and eosin staining.

\section{Cell labeling and Prussian blue staining}

Passage 3 GFP-ADSCs were labeled with SPIO (Advanced Magnetics, Cambridge, MA), using previously established methods. ${ }^{18}$ The polyamine, poly-l-lysine (PLL) hydrobromide (Sigma) was used as the transfection agent. The final SPIO concentration used for labeling was $25 \mu \mathrm{g} / \mathrm{mL}$. The cells were labeled at $37^{\circ} \mathrm{C}$, incubated in a $5 \% \mathrm{CO}_{2}$ incubator for 24 hours, and repeatedly washed with phosphate buffer solution. A small aliquot of labeled cells was fixed with $4 \%$ paraformaldehyde for 20 minutes, washed three times, and incubated with $2 \%$ potassium ferrocyanide (Perl's reagent) in $6 \%$ hydrochloric acid for 30 minutes. After another wash, the cells were counterstained with Nuclear Fast Red. The cells without SPIO were used as the control group.

\section{TEM of labeled cells}

GFP-ADSCs were analyzed by transmission electron microscopy (TEM,10 CR, Carl Zeiss, Oberkochen, Germany) to evaluate SPIO internalization further. The labeled cells were fixed in $3 \%$ glutaraldehyde-cacodylate buffer at $48^{\circ} \mathrm{C}$ overnight. After one hour of incubation in $1 \% \mathrm{OsO}_{4}$, the cells were dehydrated in graded ethanol dilutions, embedded in artificial resin (Epon, Merck, Darmstadt, Germany) and processed for TEM. The thin cellular sections embedded in artificial resin were evaluated in their unstained form to prevent false-positive findings. TEM was performed at $60-80 \mathrm{kV}$.

\section{Viability of labeled cells}

SPIO-labeled GFP-ADSCs viability was evaluated using a cell counting kit-8 (CCK-8, Dojindo Laboratories, Kumamoto, Japan) following the manufacturer's instructions. GFP-ADSCs were first inoculated in 96-well plates $\left(3 \times 10^{3}\right.$ cells per well $)$ at $37^{\circ} \mathrm{C}$ and $5 \% \mathrm{CO}_{2}$. After 24 hours, the final concentrations of SPIO $(25,50$, and $100 \mu \mathrm{g} / \mathrm{mL}$ ) were added to each well with six other duplicates and incubated for 24 hours. The remaining cells were not labeled with the complex and served as a control group, to which $10 \mu \mathrm{L}$ of CCK-8 were added per well for 2 hours. Absorbance was then measured at a wavelength of $450 \mathrm{~nm}$. The toxicity of the labeled GFP-ADSCs was further examined by flow cytometric detection of cell cycles and apoptosis. Labeled and unlabeled cells were stained with propidium iodide for apoptosis tests. The cell cycle profiles, including G0-G1, G2-M, and S phases, and subG1 fraction, were analyzed.

\section{In vitro MRI of labeled cells}

The labeled cells were washed in phosphate buffer solution, trypsinized, and suspended in $1 \%$ agarose gel to $0.5 \times 10^{6}$, $1 \times 10^{6}$, and $2 \times 10^{6}$ cells $/ \mathrm{mL}$, and unlabeled control cells were $1 \times 10^{6}$ cells $/ \mathrm{mL}$. A $3 \mathrm{~T}$ Signa HDxt superconductor clinical magnetic resonance system (GE Medical Systems, Milwaukee, WI) was used with a standard knee coil. T2-weighted images were acquired using a fast spin echo sequence repetition time $2300 \mathrm{msec}$, echo time $77.3 \mathrm{msec}$, and echo train 12. All images were acquired with a field of view of $120 \mathrm{~mm} \times 120 \mathrm{~mm}$, a data matrix of $256 \times 256$, and a slice thickness of $2 \mathrm{~mm}$, and used nine slices. Orientation was in the supine position and head first.

\section{Animal models and cell transplantation}

Six-week-old C57/BL6 male mice $(n=20)$ were obtained from Shanghai SLAC Laboratory Animal Co, Ltd. All animal protocols were approved by the Animal Experiment and Care Committee of Shanghai Jiao Tong University School of Medicine. Mice suffering from acute left common carotid artery injuries were used as the recipient animals for cell transplantation. Guidewire injury of the left common carotid artery was performed as previously described. ${ }^{19}$ The mice were anesthetized with chloral hydrate $20 \mathrm{mg} / \mathrm{kg}$. The left carotid artery bifurcation was exposed via a midline incision of the ventral neck. After temporary internal and common carotid artery occlusion, a pediatric scalp needle was used to puncture the middle of the external carotid artery. A modified elastic guidewire with a 0.014 inch diameter was used to pierce the external carotid artery, and continued through the arterial branch until reaching the proximal end of the common carotid artery. The guidewire was traced back and forth three times to peel off the common carotid artery endothelium fully. After guidewire removal, the proximal external carotid artery ligature was tied off. Normal blood flow was assured, and the skin was closed with a single suture using $5 / 0$ silk. The mice $(n=6)$ received either $1 \times 10^{6}$ labeled or unlabeled GFP-ADSCs by intravenous tail vein injection immediately after induction of arterial injury.

\section{In vivo MRI tracking of labeled GFP- ADSCs}

The animals underwent clinical $3 \mathrm{~T}$ MRI with a rodent receiver coil (Shanghai Chenguang Medical Technology Corporation, Shanghai, China) immediately before and 1, 3, 7, 14, 21, and 30 days after labeled or unlabeled GFP-ADSCs transplantation. Following induced anesthesia, the mouse to be imaged was placed inside the MRI receiver coil. Two-dimensional FRFSE 
T2-weighted magnetic resonance images were obtained using the following parameters: repetition time/echo time 2500/82.8 msec, echo train 12, slice thickness $2 \mathrm{~mm}$, field of view $6.0 \times 6.0 \mathrm{~cm}$, matrix $256 \times 256$, and four excitations.

\section{Histology and immunohistochemistry}

After MRI at 7 and 30 days, three mice were sacrificed for histological examination. The injured and common carotid arteries were subjected to fast-frozen sectioning, cut into $8 \mu \mathrm{m}$ sections with cryostat, and collected on poly-D-lysine coated slides. The lesion site was identified on day 7 , and a length of fixed arteries extending for $0.3 \mathrm{~cm}$ on either side was removed. The selected blocks were trimmed, and the thin sections were cut for TEM analysis to assess for SPIO-labeled GFP-ADSCs. All sections were subjected to Prussian blue staining and fluorescence immunohistochemistry. After permeabilization in $0.3 \%$ Triton-X100 diluted in phosphate buffer solution, the sections were incubated with $10 \%$ goat serum albumin diluted in bovine serum albumin (Abcam) for 30 minutes at $37^{\circ} \mathrm{C}$ to block nonspecific antibody adhesion. The primary antibodies to CD31 (rabbit polyclonal, 1:200 diluted in 0.5\% bovine serum albumin), F4/80 (rat monoclonal, 1:200 diluted in bovine serum albumin), and MAC-3 (rat monoclonal, 1:200 diluted in bovine serum albumin) were incubated at $4^{\circ} \mathrm{C}$ overnight. After rinsing in phosphate buffer solution, an Alexa Fluor ${ }^{\circledR} 555$ (goat antirabbit or goat anti-rat, 1:500 diluted in bovine serum albumin, Invitrogen, Carlsbad, CA) was applied and incubated for one hour at $37^{\circ} \mathrm{C}$ in the dark. After further washes in phosphate buffer solution, the cell nuclei were counterstained with $4^{\prime}$, 6-diamidino-2-phenylindole (DAPI, 1:500, diluted in bovine serum albumin, DAKO, Carpinteria, CA) for 10 seconds. After a final wash in phosphate buffer solution, the sections were mounted in distilled water and examined under a fluorescence microscope (Nikon, Japan). All images were digitally recorded and the numbers of positive cells in five random fields were calculated, and processed with Image-Pro Plus (Media Cybernetics Inc, Rockville, MD).

\section{Statistical analysis}

The data were expressed as the mean \pm standard deviation. For quantitative comparison and analysis, the values were subjected to a Student's $t$-test and one-way analysis of variance. $P<0.05$ was regarded as statistically significant.

\section{Results}

\section{Characterization of GFP-ADSCs}

The initially adherent cells grew into spindle-shaped or stellate-shaped cells, which then developed into visible colonies 2 days after initial plating (Figure 1A). Green fluorescence was observed under fluorescence microscopy (Figure 1B). The cells began to proliferate rapidly and were passaged by trypsin every 2 days until $90 \%$ confluence was reached. At the third passage, GFP-ADSCs adopted a more uniform fibroblast-like shape (Figure 1C), similar to bone marrow stromal cells. Green fluorescence was also observed under fluorescence microscopy (Figure 1D). The expression of different cell surface markers, including CD11b, CD31, CD34, CD83, CD90, CD105, and CD133 of passage 3 GFP-ADSCs, was determined by flow cytometry. Passage 3 GFP-ADSCs were positive for CD90 and CD105, but negative for CD11b, CD31, CD34, CD83, and CD133 (Figure 2).

\section{Multipotent differentiation of GFP-ADSCs}

In this study, GFP-ADSCs could be induced to differentiate along the osteogenic, adipogenic, and chondrogenic lineages using special culture media. Cells with bone-forming capacity were examined by Alizarin Red (Figure 3A). Adipogenic differentiation was confirmed following the standard protocol and analyzed by Oil Red-O staining. Red-colored oil granules in adipogenic cultures were observed (Figure 3B). For chondrogenic differentiation, histological and hematoxylin and eosin staining results showed that cartilage lacunae were formed (Figure 3D) and expressed the chondrocyte gene marker, collagen II (Figure 3C).

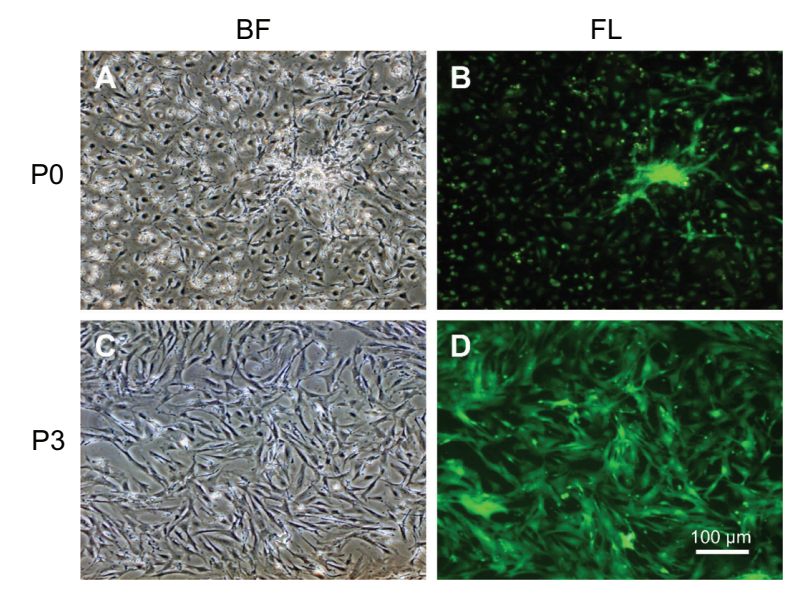

Figure I Morphology of GFP-ADSCs from subcutaneous fat pads cultured in vitro. (A) After being plated in a Petri dish for 24 hours, the primary adherent cells grew into spindle-shaped or stellate-shaped cells. (B) Green fluorescence of (A) was observed under fluorescence microscopy. (C) At the third passage, the GFP-ADSCs appeared to adopt a more uniform fibroblast-like shape with directionality and regularity. (D) Green fluorescence of $\mathrm{C}$ was observed under fluorescence microscopy. Note: Scale bar measures $100 \mu \mathrm{m}$.

Abbreviations: GFP-ADSCs, green fluorescent protein adipose-derived stem cells; $\mathrm{BF}$, bright field; FL, fluorescent light. 

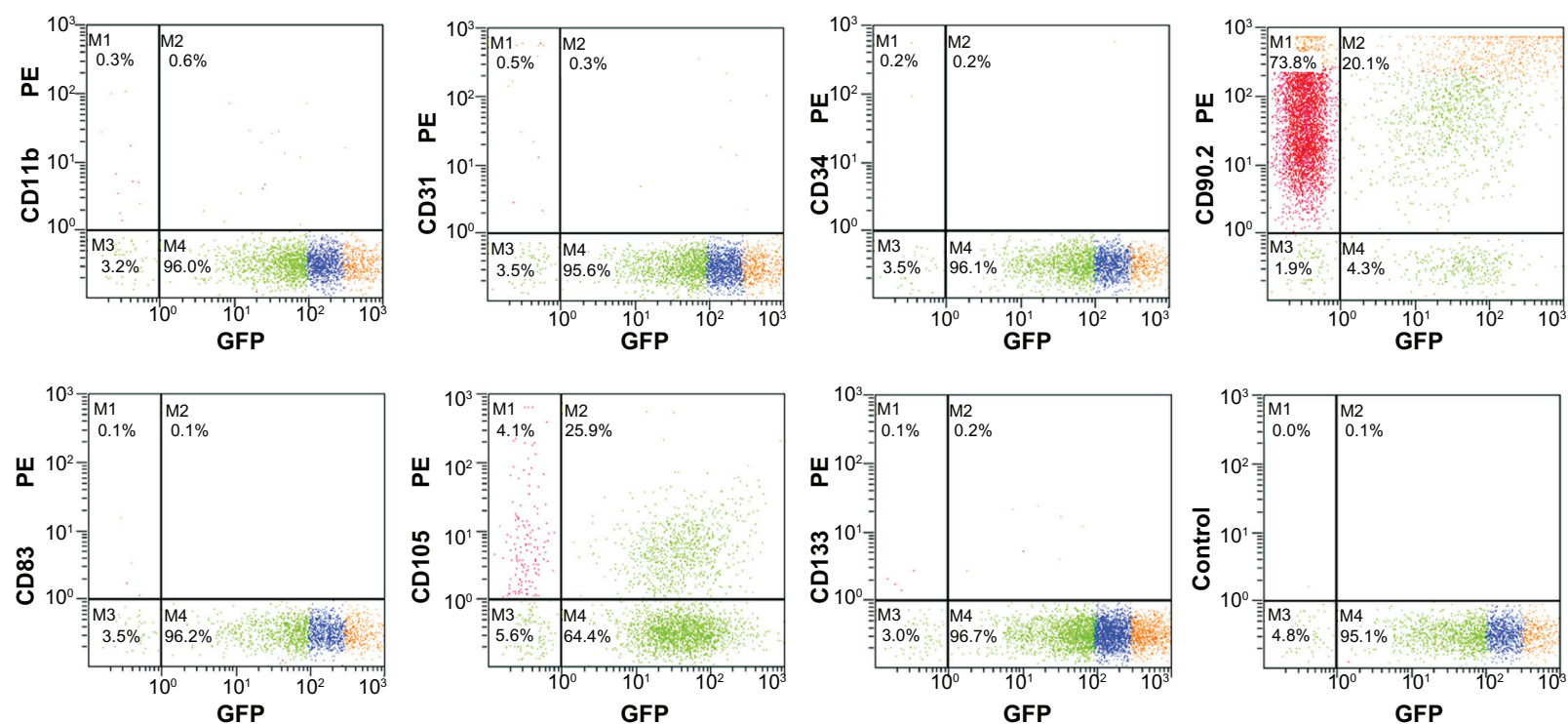

Figure 2 Flow cytometry analysis of GFP-ADSC surface antigen, CD90, and CDI05 were positive, whereas CDIIb, CD3I, CD34, CD83, and CDI33 were negative, and the isotype control was also negative.

Abbreviation: GFP-ADSCs, green fluorescent protein adipose-derived stem cells.

\section{Prussian blue staining and TEM examination}

GFP-ADSCs were cultured with SPIO for 24 hours, and almost all cells contained blue particles in the cytoplasm after Prussian blue staining (Figure 4A). Labeling efficiency was approximately $100 \%$, which was calculated under a light microscope by counting the numbers of positive cells in five random fields (Figure 4A). In contrast, no stainable iron was detected in the unlabeled cells (Figure 4B). Fluorescence microscopy (Figure S1) revealed GFP distribution within the labeled and unlabeled cells. The TEM results indicated that the iron particles accumulated in endosomes/lysosomes (Figure 4C).

\section{Cell viability of labeled GFP-ADSCs}

The growth curve for CCK-8 with SPIO-labeled GFP-ADSCs showed cell proliferation in the $25 \mu \mathrm{g} / \mathrm{mL}$ and $50 \mu \mathrm{g} / \mathrm{mL}$ concentration subgroups, and the results were not statistically significant $(P>0.05)$ compared with those of the unlabeled cells. Until the SPIO concentration reached $100 \mu \mathrm{g} / \mathrm{mL}$, the relative proliferation level of the labeled GFP-ADSCs was somewhat inhibited $(P<0.05$, Figure $4 \mathrm{D})$, indicating that at concentrations $<50 \mu \mathrm{g} / \mathrm{mL}$, SPIO did not affect cell viability. To investigate the influence of SPIO on cell apoptosis, the treated cells were analyzed by flow cytometry (Figure S2) and cell phase distribution was analyzed by determination of DNA contents (Figure S3). In this study, we chose the safer concentration of $25 \mu \mathrm{g} / \mathrm{mL}$ to label GFP-ADSCs efficiently, which is suitable for GFP-ADSCs labeling in future cell therapies, and consistent with previous reports. ${ }^{20}$

\section{In vitro MRI of labeled GFP-ADSCs}

GFP-ADSCs $\left(0.5 \times 10^{6}, 1 \times 10^{6}\right.$, and $2 \times 10^{6}$ cells $\left./ \mathrm{mL}\right)$ labeled with SPIO $(25 \mu \mathrm{g} / \mathrm{mL})$ were detected by in vitro $3 \mathrm{~T}$ MRI. The iron-labeled cells, but not the unlabeled control cells, showed a signal drop in the T2-weighted images (Figure 5A). With increasing numbers of labeled cells, the MRI signal was gradually reduced (Figure 5B), as indicated by the histogram.

\section{In vivo MRI tracking of labeled GFP- ADSCs}

In this study, clinical $3 \mathrm{~T}$ MRI was performed on days 1, $3,7,14,21$, and 30 after injection of labeled $(25 \mu \mathrm{g} / \mathrm{mL})$ or unlabeled GFP-ADSCs (Figure 6A). In the T2-weighted images, the injured area appeared bright due to the ablated cells. However, the labeled stem cells appeared darker due to a signal drop. At days 1 and 3 after transplantation, the MRI signal values showed a modest reduction, but the difference was not statistically significant $(P>0.05)$. This result suggests newly initiated homing of the SPIO-labeled GFPADSCs. Seven days after transplantation, the MRI signal values (Figure 7) showed a statistically significant $(P<0.05)$ reduction compared with those before transplantation. Similarly, 14 and 21 days after transplantation, the signal in the experimental group remained lower compared with that 

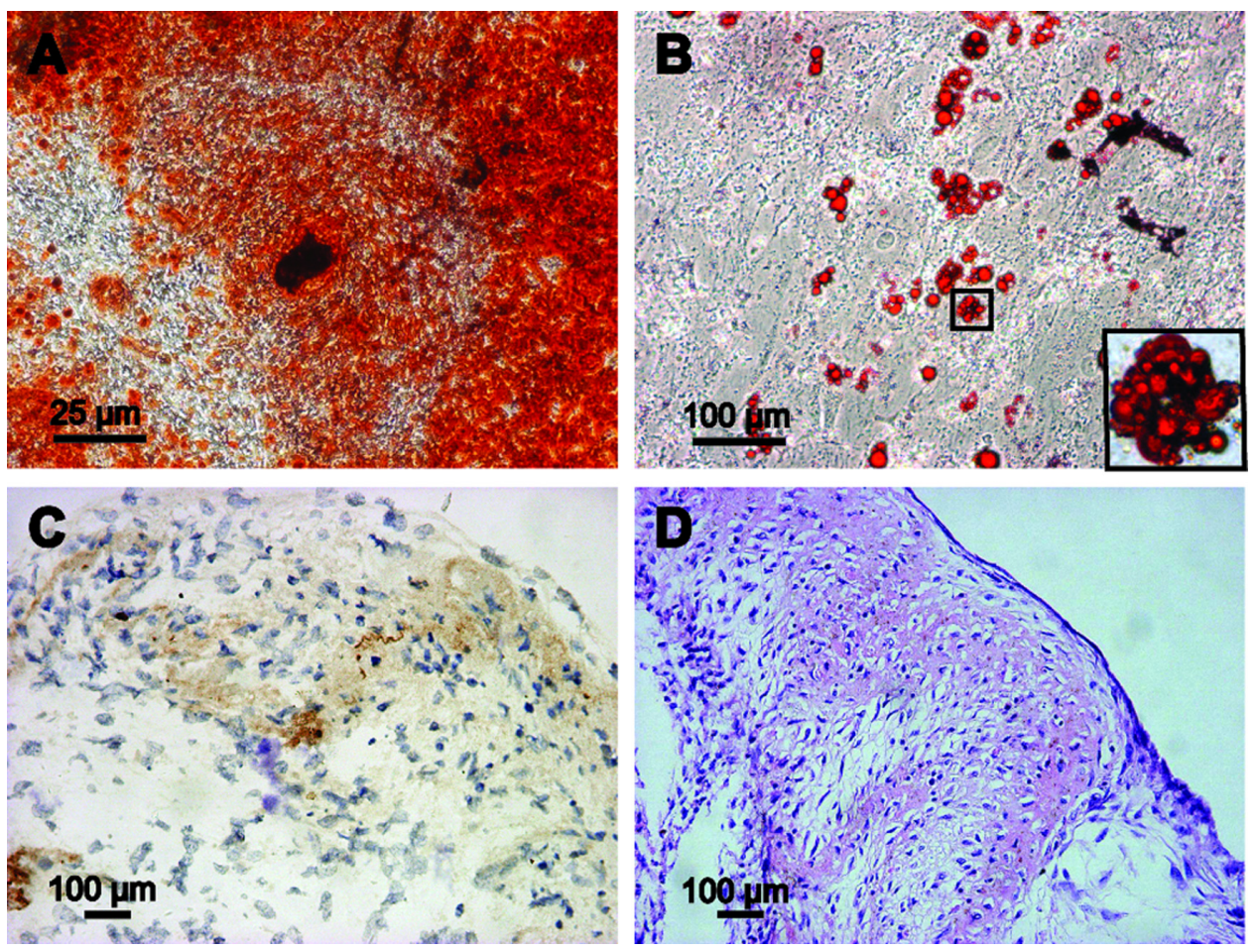

Figure 3 Multipotent differentiation of GFP-ADSCs. (A) Alizarin Red detected calcium mineralization in osteogenic cultures of GFP-ADSCs for 3 weeks in vitro. (B) Oil Red O staining detected red-colored oil granules in adipogenic cultures of GFP-ADSCs (magnified view of the square area in [B]). (C and D) For chondrogenic differentiation, histological and hematoxylin and eosin staining results showed that cartilage lacunae were formed and expressed chondrocyte gene markers, collagen II (C and $\mathbf{D}$ ).

Notes: Scale bar A measures $25 \mu \mathrm{m}, \mathrm{B}, \mathrm{C}$, and D measure $100 \mu \mathrm{m}$.

Abbreviation: GFP-ADSCs, green fluorescent protein adipose-derived stem cells; HE, hematoxylin and eosin.
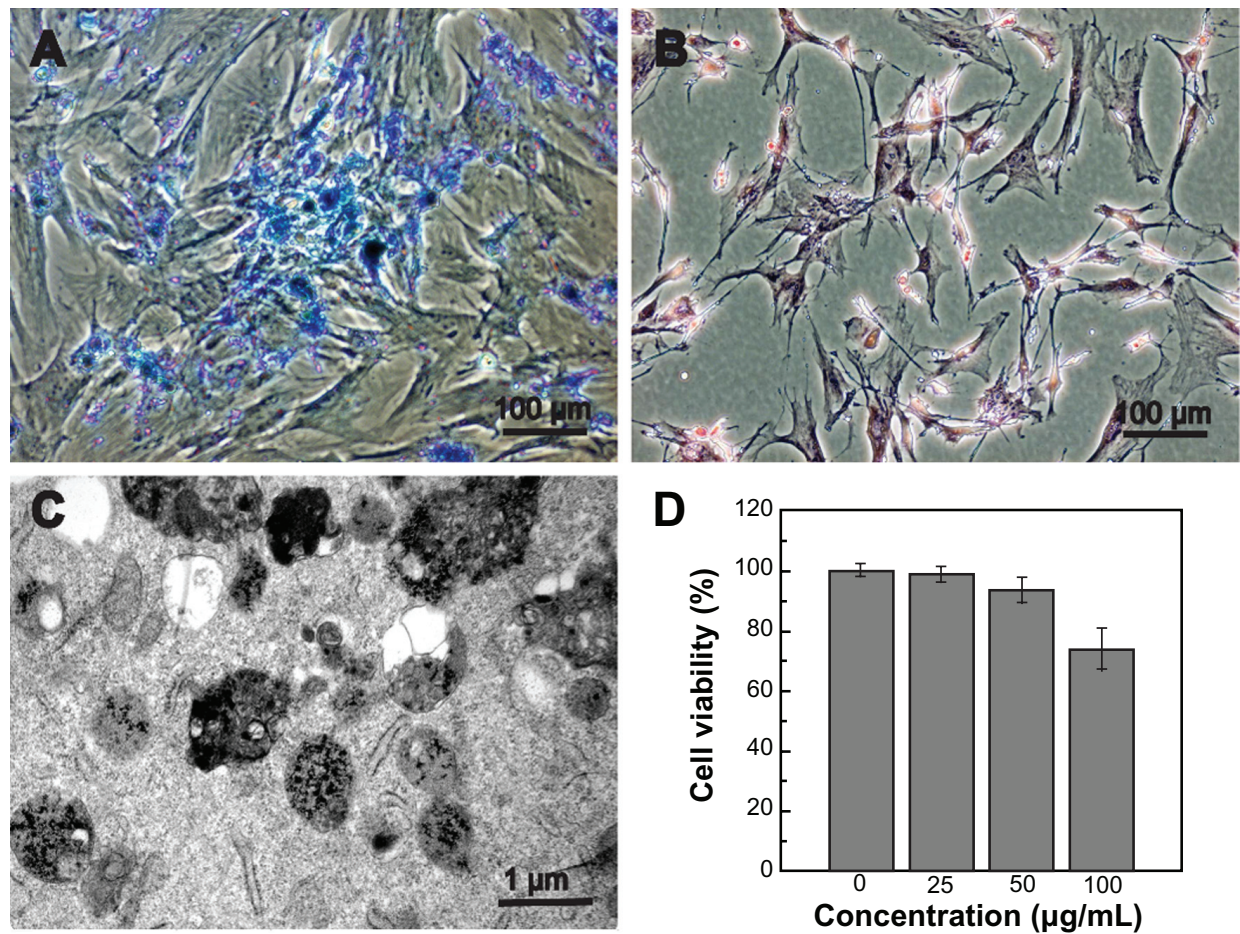

Figure 4 Prussian blue staining, TEM examination, and cell viability of labeled GFP-ADSCs. (A) Prussian blue staining showed numerous blue-stained iron particles in the cytoplasm in nearly $100 \%$ of cells. (B) No stainable iron was detected in unlabeled cells. (C) TEM results indicates that the iron particles accumulated in the endosomes/ lysosomes. (D) CCK-8 assay results showed that cell viability was not affected by SPIO at iron concentrations less than $50 \mu \mathrm{g} / \mathrm{mL}$.

Note: Scale bar measures $100 \mu \mathrm{m}$.

Abbreviations: TEM, transmission electron microscopy; CCK-8, cell counting kit-8; SPIO, superparamagnetic iron oxide particles; GFP-ADSCs, green fluorescent protein adipose-derived stem cells. 


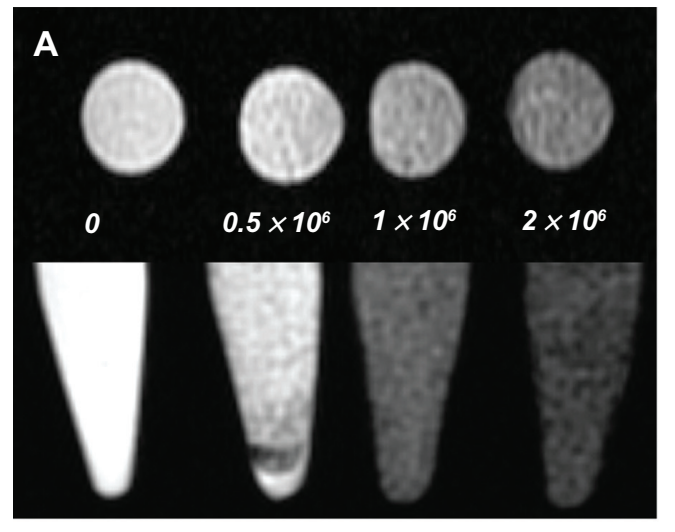

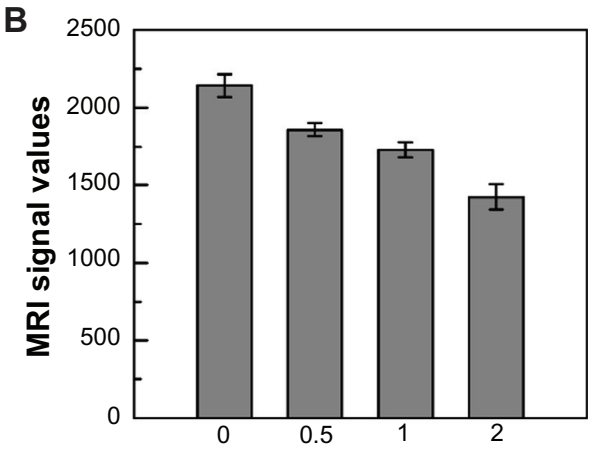

Cell number $\left(\times 10^{6}\right)$

Figure 5 Magnetic resonance imaging of SPIO-labeled GFP-ADSCs in vitro. (A) Different cell populations labeled with SPIO were visible on T2-weighted images. (B) MRI signal intensity of labeled cells was inversely correlated with the number of labeled GFP-ADSCs in $\mathrm{T}_{2}$-weighted images in vitro.

Abbreviations: GFP-ADSCs, green fluorescent protein adipose-derived stem cells; MRI, magnetic resonance imaging; SPIO, superparamagnetic iron oxide particles.

before transplantation, and gradually increased to normal levels on day 30. Our results show that the SPIO-labeled GFP-ADSCs homed to the injured common carotid artery site. In the control group, the MRI signal values after GFPADSCs transplantation were not significantly different from those before transplantation.

\section{Histological examination}

We performed Prussian blue staining and TEM at the imaged sites of injury in vivo 7 days after cell transplantation to determine the ability of the labeled GFP-ADSCs to home to and participate in repairing the injured artery tissue. The Prussian blue staining results show several blue-positive cells scattered in and around the lesion sites in the experimental group (Figure 8A). The TEM results further demonstrate that the iron particles accumulated at the sites of injury (Figure 8C). In contrast, no stainable iron was detected in the control groups (Figure S4). Moreover, fluorescent microscopic examination detected GFP-expressed cells in the injured left carotid artery sites (Figure 8B), which gradually migrated toward the tunica media and adventitia over time (Figure 9B). Several GFP-ADSCs attached to the injured endothelium and differentiated into endothelium as confirmed by CD31 (red) and GFP (green) double staining (Figure 8B). However, at the end of the experiment (30 days), blue-positive cells around the injured areas were limited (Figure 9A), which correlated well with the MRI findings (Figure 6G). The number of stained positive cells reached a maximum on day 7 , and gradually declined thereafter. This result is consistent with the in vivo MRI results (Figure 7).
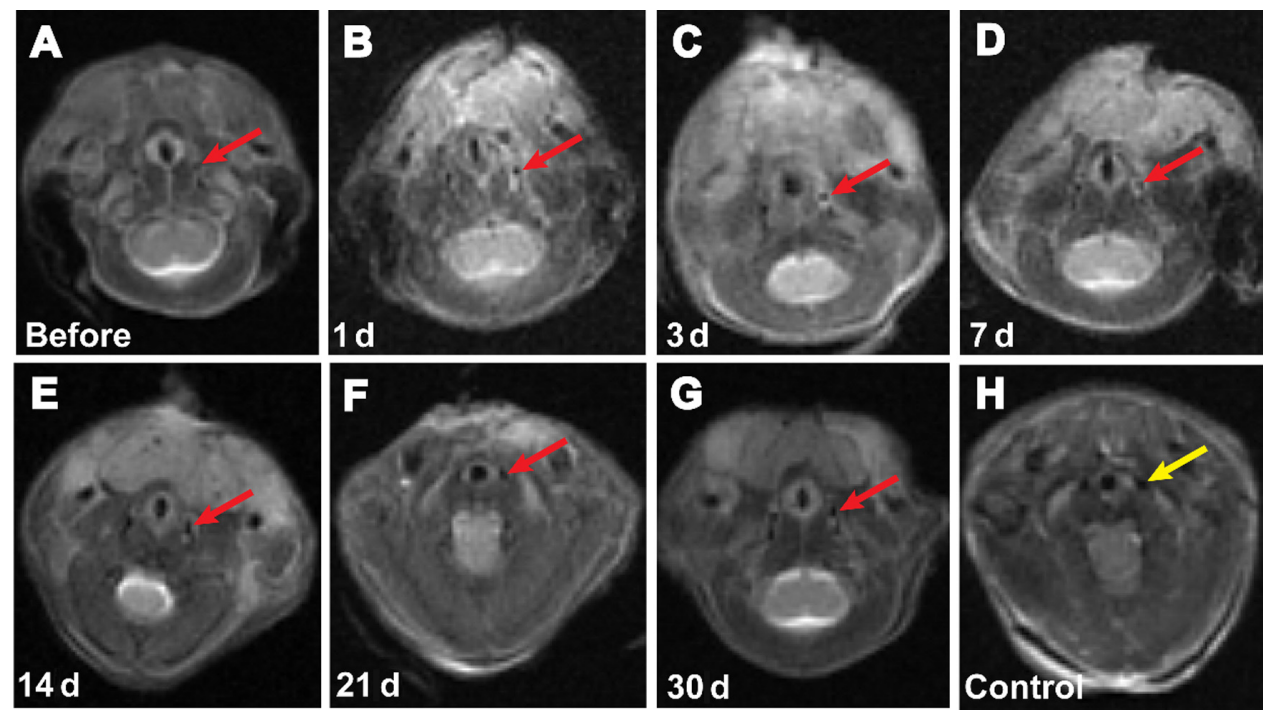

Figure 6 Representative T2-weighted magnetic resonance images of C57BL/6 mice transplanted with GFP-ADSCs. SPIO-labeled GFP-ADSCs in the left carotid artery area (arrows) before $(\mathbf{A})$, I day $(\mathbf{B}), 3$ days $(\mathbf{C}), 7$ days $(\mathbf{D}), 14$ days $(\mathbf{E}), 2$ I days $(\mathbf{F}), 30$ days $(\mathbf{G})$, and control $(\mathbf{H})$ after transplantation.

Abbreviation: GFP-ADSCs, green fluorescent protein adipose-derived stem cells. 


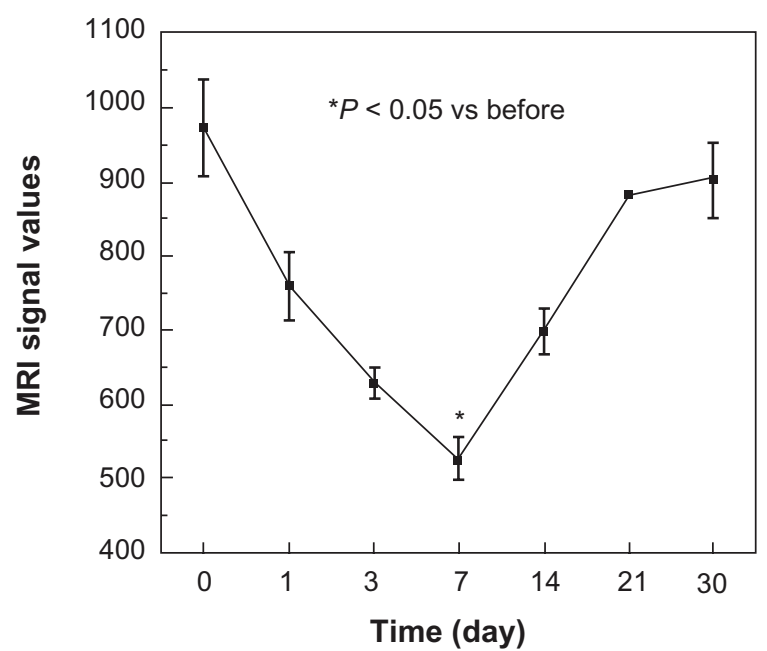

Figure 7 Magnetic resonance imaging (MRI) signal intensity curves obtained from the local vascular wall of the injured common carotid artery.

Notes: At days I and 3, the MRI signal values showed a modest reduction, and statistically significant changes in signal levels were observed at 7 days $(P<0.05)$, as indicated by the curve. Afterwards, the signal levels gradually increased to normal levels on day 30 .

In contrast, no cells were positively stained with Prussian blue in the control group. In this study, macrophages were also identified with F4/80 (Figures $8 \mathrm{D}$ and $9 \mathrm{C}$ ) and MAC-3 (Figure S5), which can take up SPIO released into the extracellular environment. ${ }^{32}$ Macrophages were detected at 7 days and their numbers had obviously decreased at 30 days.

\section{Discussion}

Adipose tissue, like bone marrow, contains a great deal of stromal stem cells, which can be easily isolated and expanded in vitro. ${ }^{7,23}$ Direct comparisons between ADSCs and bone marrow stem cells immune phenotypes reveal that they are $90 \%$ identical. ${ }^{21}$ ADSCs have a stronger proliferation ability and multidifferentiation potential than bone marrow stem cells. ${ }^{7}$ The ADSCs surface marker HLA-DR is also negative, which implies low immunogenicity. ${ }^{22}$ ADSCs can be used autologously without breaching any ethical standards. ${ }^{23}$ In this study, passage 3 GFP-ADSCs were positive for CD90 and CD105, but negative for CD11b, CD31, CD34, CD83, and CD133. Passage 3 GFP-ADSCs also have the ability to differentiate into a number of mesodermal lineages, including osteoblasts, adipocytes, and chondrocytes, which is consistent with previous reports. ${ }^{17}$ ADSCs are also capable of differentiating into other mesodermal cell types under chemical induction. ${ }^{24,25,36}$ Humans have abundant subcutaneous adipose tissue, which can be easily isolated by liposuction procedures in the clinic. Therefore, ADSCs are increasingly becoming an ideal candidate for cellular therapy, and will have far-reaching effects in repairing and regenerating damaged or diseased tissues and organs.

The location, migration, distribution, and long-term viability of transplanted cells at their targets must be noninvasively evaluated in vivo for effective cell therapies. The recent development of molecular imaging technologies has made in vivo dynamic monitoring and detecting the destiny of transplanted cells a realistic goal. MRI has the advantages of high temporal and spatial resolution and sharp contrast, ${ }^{9}$ and has an ability to monitor the migration and homing of transplanted cells to injured tissues and organs in vivo. ${ }^{26}$ MRI contrast agents such as SPIO have been widely used for tracking stem cells in various organ injuries..$^{27,28} \mathrm{In}$ this study, we used PLL as a transfection agent to label GFPADSCs magnetically in vitro with commercially available SPIO approved by the Food and Drug Administration. CCK-8 analysis of the cytotoxicity and viability of different SPIO concentrations was performed on GFP-ADSCs. A SPIO concentration $<50 \mu \mathrm{g} / \mathrm{mL}$ was relatively safe and effective for GFP-ADSCs labeling, which agrees well with previous research. ${ }^{18,29}$ In this study, we chose the safer concentration of $25 \mu \mathrm{g} / \mathrm{mL}$ to label GFP-ADSCs efficiently. Labeling efficiency was assessed by Prussian blue staining, and the results showed that almost all cells were successfully labeled. Taking together the combination of cell phenotype observation, CCK- 8 assay of cell viability, and flow cytometric analysis of cell apoptosis and cycles shows that SPIO at a concentration of $25 \mu \mathrm{g} / \mathrm{mL}$ are noncytotoxic and should be suitable for use in future cell therapy. PLL-SPIO do not affect the phenotype, viability, or proliferation of GFPADSCs, which is consistent with earlier reports.$^{20}$ However, several previous studies have found that PLL-SPIO labeling of mesenchymal stem cells slightly impairs chondrogenic differentiation capability. ${ }^{30}$ All labeled cells were visible on T2-weighted images because they caused a signal decrease. With increasing numbers of labeled cells, the MRI signal is gradually reduced.

The ability to image cellular migration in vivo is very useful for studying the effects of cell therapy. Cells labeled with SPIO can be imaged for several weeks using MRI. ${ }^{10,31}$ In this study, the migration and distribution of labeled GFPADSCs after intravenous transplantation were dynamically monitored for 30 days using clinical 3 T MRI. At days 1 and 3, the MRI signal values showed a modest reduction. Statistically significant signal level changes were observed at 7 days $(P<0.05)$, as indicated by the histogram, and gradually increased to normal levels by day 30 . No similar signal drops were seen in the control groups. Corresponding findings were 

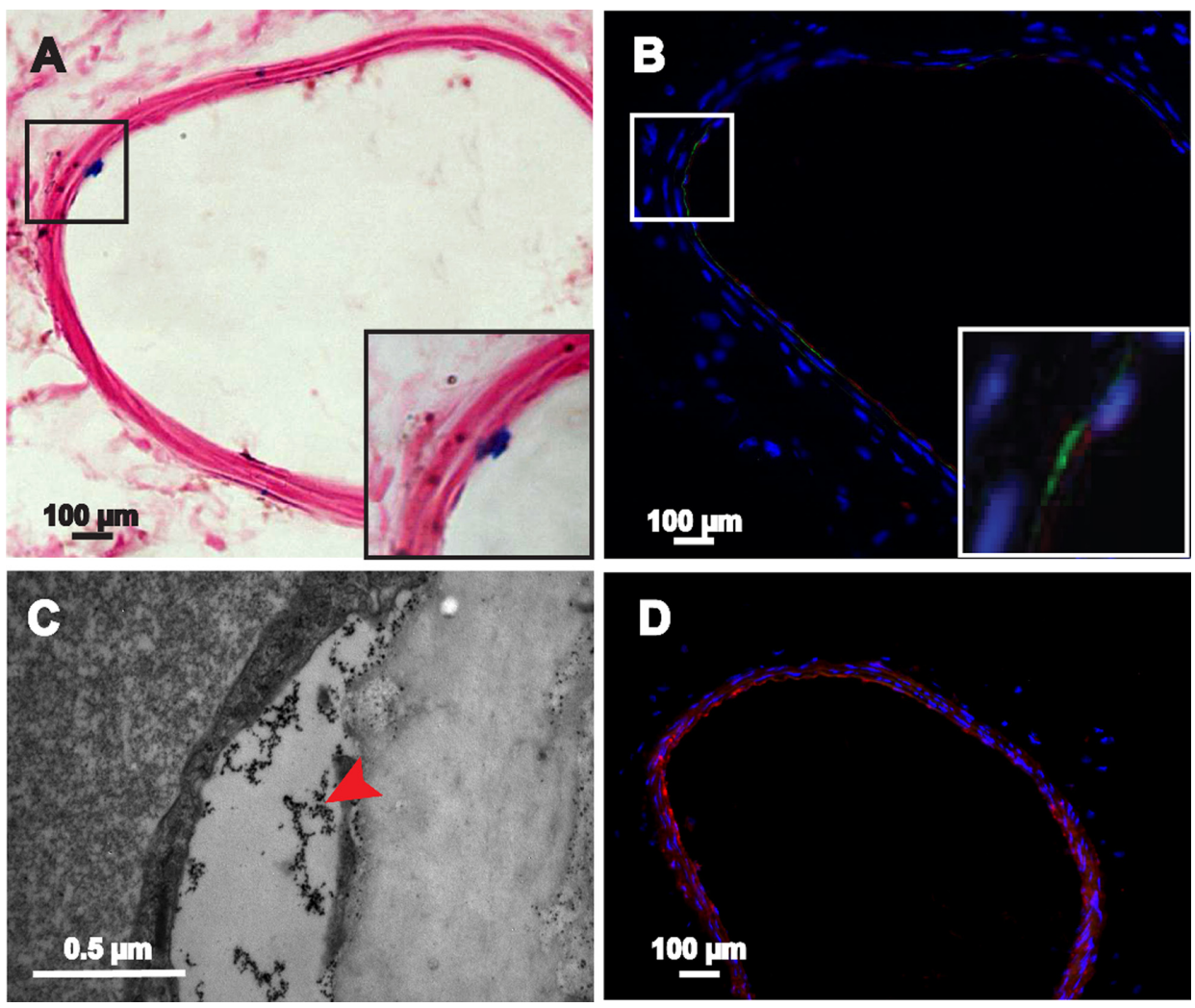

Figure 8 Histological examination of the injured carotid artery 7 days after transplantation. (A) Blue-stained particles were observed in the lesion area (magnified view of the square area in [A]). (B) GFP-ADSCs homing into the injured lesions and differentiated into endothelium were visualized using fluorescence microscopy of GFP and CD3I (red) after nuclear staining with DAPI (magnified view of the square area in [B]). (C) TEM results indicate that the iron particles accumulated in the lesion area. (D) Macrophage mark F4/80 (red) could be detected at 7 days.

Note: Scale bar A, B, and D measure $100 \mu \mathrm{m}$; C measures $0.5 \mu \mathrm{m}$.

Abbreviations: DAPI, 4', 6-diamidino-2-phenylindole; GFP-ADSCs, green fluorescent protein adipose-derived stem cells; TEM, transmission electron microscopy.

also confirmed by Prussian blue staining and fluorescence immunohistochemistry at days 7 and 30. In this study, the GFP-ADSCs attached to the injured endothelium and differentiated into endothelium, as confirmed by CD31 and GFP double staining. However, the available number of cells is limited. GFP-ADSCs contributed to re-endothelialization of the injured artery, but the underlying mechanisms are unclear. At days 30 , no significant signal intensity loss was observed at the site of arterial injury, whereas Prussian blue staining results revealed several blue-positive cells, which may be because the iron oxide particles were diluted after cell proliferation. MRI that is solely dependent on iron oxide is deficient in monitoring stem cell proliferation and differentiation. ${ }^{32}$ The results of our investigations demonstrated the potential use of in vivo molecular MRI to monitor the migration and homing of labeled GFP-ADSCs to injured artery walls.
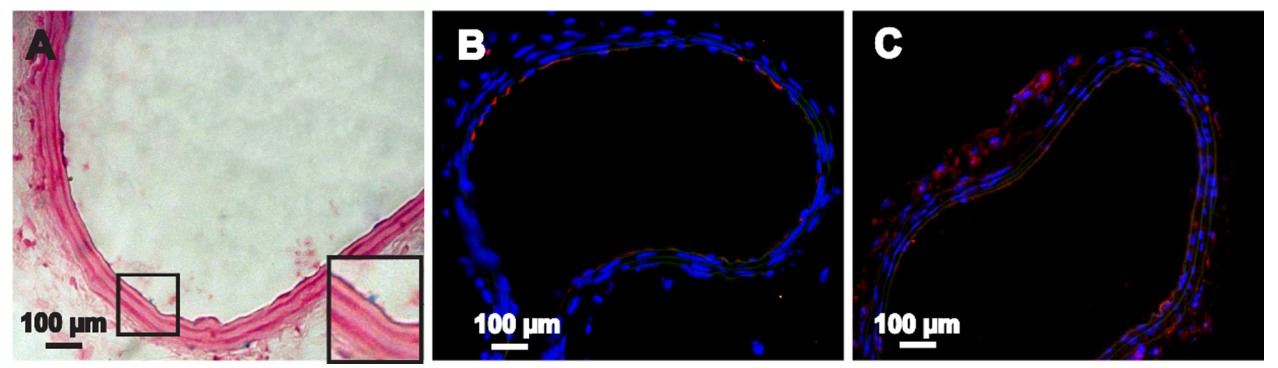

Figure 9 Histological examination of the injured carotid artery 30 days after transplantation. (A) Blue-stained particles were observed in the lesion area (magnified view of the square area in [A]). (B) GFP-ADSCs homing into the injured lesions were visualized and assayed by fluorescence microscopy of GFP and CD3। (red) after nuclear staining with DAPI. (C) The macrophage marker F4/80 (red) could be detected after 30 days.

Note: Scale bar measures $100 \mu \mathrm{m}$.

Abbreviation: GFP-ADSCs, green fluorescent protein adipose-derived stem cells; DAPI, 4', 6-diamidino-2-phenylindole. 
However, whether loss of signal intensity is due to cellular migration to neighboring organs, dead cells, contrast agent biodegradation, or the presence of hemosiderin during hemorrhage remains controversial. ${ }^{32}$ Prussian blue staining cannot distinguish these possibilities because it detects iron particles regardless of the source. In this study, macrophages were also identified because they surround the SPIO released into the extracellular environment. Hence, this phenomenon contributes to MRI signal loss. Macrophages were detected at 7 days and their numbers decreased thereafter. Some researchers have argued that after uptake of dead cells or iron particles by macrophages, the iron content is quickly metabolized or degraded, and $95 \%$ of the reduction in local MRI signal is due to the loss of labeled cells. ${ }^{32}$

GFP has traditionally been a gene marker of choice and has been developed to assist researchers in investigating cell therapies..$^{33}$ In this study, SPIO was used to label GFPADSCs, and GFP fluorescence was used to confirm the findings by dynamically tracking MRI results further. GFP can verify the presence of living stem cells at injury sites and can eliminate other factors, such as hemorrhage and dead cells. ${ }^{14}$ In this study, labeled cells could be dynamically detected on an ongoing basis using clinical 3 T MRI and fluorescence microscopy. Dual labeling of GFP living cells with iron oxides can be used to detect and track cells in vivo. Hence, our understanding and implementation of gene-cell mediated therapies has been improved.

The mechanism involved in homing of GFP-ADSCs to arterial lesions remains unclear. Several factors have been suggested to cause mobilization and homing of stem cells during endothelial injury, including paracrine secretion by transplanted cells, chemokines, and adhesion molecules of the selectin and integrin families. ${ }^{34-36}$ Further, previous studies have also recognized that an inflammatory reaction contributes to the homing of stem cells. ${ }^{37}$

\section{Conclusion}

In summary, a commercially available SPIO approved by the US Food and Drug Administration was used to label GFP-ADSCs effectively without any adverse effects on cell phenotype, viability, and GFP expression in vitro. Noninvasive $3 \mathrm{~T}$ MRI in vivo can dynamically monitor labeled GFP-ADSCs homing into mouse carotid artery lesions after cell transplantation on an ongoing basis. Our findings were confirmed by Prussian blue staining and fluorescence immunohistochemistry examination at different time points during the study. This technical development represents a valuable and novel step for dual labeling of cells with magnetic oxides and specific gene expression in the future. This result also enhances our understanding of cell-based therapeutic strategies for vascular diseases.

\section{Acknowledgments}

This research was supported by the National Natural Science Foundation of China (30772104), the Natural Science Foundation of Shanghai Science and Technology Committee (11ZR1429300), the Medical Guiding Program of Shanghai Science and Technology Committee (1141190800), the Songjiang Medical Climbing Program, Shanghai, China (2011PD04), and the Ningbo Natural Science Foundation (2008A610093).

The authors appreciated the kind support of Professor Zun-li Shen, Yu-qing Jin, De-min Yin, Li-juan Zong, Juanjuan Wu, Jing-jun Chen, and Wan-yao Xia.

\section{Disclosure}

The authors report no conflicts of interest in this work.

\section{References}

1. Nissen SE, Tuzcu EM, Schoenhagen P, et al. Effect of intensive compared with moderate lipid-lowering therapy on progression of coronary atherosclerosis - a randomized controlled trial. JAMA. 2004; 291:1071-1080.

2. Yerramasu A, Dey D, Venuraju S, et al. Increased volume of epicardial fat is an independent risk factor for accelerated progression of sub-clinical coronary atherosclerosis. Atherosclerosis. 2012;220: 223-230.

3. Nikol S. Therapeutic angiogenesis using gene transfer and stem cell therapy in peripheral artery disease. Dtsch Med Wochenschr. 2011; 136:672-674. German.

4. Yvan-Charvet L, Pagler T, Gautier EL, et al. ATP-binding cassette transporters and HDL suppress hematopoietic stem cell proliferation. Science. 2010;328:1689-1693.

5. Derubeis AR, Cancedda R. Bone marrow stromal cells (BMSCs) in bone engineering: limitations and recent advances. Ann Biomed Eng. 2004;32:160-165.

6. Schaffler A, Buchler C. Concise review: adipose tissue-derived stromal cells - basic and clinical implications for novel cell-based therapies. Stem Cells. 2007;25:818-827.

7. Zhu Y, Liu T, Song K, et al. Adipose-derived stem cell: a better stem cell than BMSC. Cell Biochem Funct. 2008;26:664-675.

8. Himmelreich U, Dresselaers T. Cell labeling and tracking for experimental models using magnetic resonance imaging. Methods. 2009;48:112-124.

9. Gatehouse PD, Keegan J, Crowe LA, et al. Applications of phasecontrast flow and velocity imaging in cardiovascular MRI. Eur Radiol. 2005; 15:2172-2184.

10. Zhu XM, Wang YX, Leung KC, et al. Enhanced cellular uptake of aminosilane-coated superparamagnetic iron oxide nanoparticles in mammalian cell lines. Int J Nanomedicine. 2012;7:953-964.

11. Sun JH, Teng GJ, Ma ZL, et al. In vivo monitoring of magnetically labeled mesenchymal stem cells administered intravascularly in rat acute renal failure. Swiss Med Wkly. 2008;138:404-412.

12. Lee ES, Chan J, Shuter B, et al. Microgel iron oxide nanoparticles for tracking human fetal mesenchymal stem cells through magnetic resonance imaging. Stem Cells. 2009;27:1921-1931. 
13. Ishii M, Numaguchi Y, Okumura K, et al. Mesenchymal stem cell-based gene therapy with prostacyclin synthase enhanced neovascularization in hindlimb ischemia. Atherosclerosis. 2009;206:109-118.

14. Qiu BS, Treuting P, Zhan XC, et al. Dual transfer of GFP gene and MGd into stem-progenitor cells toward in vivo MRI of stem cell-mediated gene therapy of atherosclerosis. Acad Radiol. 2010;17:547-552.

15. Yang X, Atalar E, Li D, et al. Magnetic resonance imaging permits in vivo monitoring of catheter-based vascular gene delivery. Circulation. 2001;104:1588-1590.

16. Taghizadeh RR, Sherley JL. CFP and YFP, but not GFP, provide stable fluorescent marking of rat hepatic adult stem cells. J Biomed Biotechnol. 2008;2008:453-590

17. Jiang T, Liu W, Lv X, et al. Potent in vitro chondrogenesis of CD105 enriched human adipose-derived stem cells. Biomaterials. 2010;31: 3564-3571.

18. Zhang Z, Mascheri N, Dharmakumar R, et al. Superparamagnetic iron oxide nanoparticle-labeled cells as an effective vehicle for tracking the GFP gene marker using magnetic resonance imaging. Cytotherapy. 2009;11:43-51.

19. Cao AH, Shi HJ, Zhang Y, et al. In vivo tracking of dual-labeled mesenchymal stem cells homing into the injured common carotid artery. Anat Rec (Hoboken). 2009;292:1677-1683.

20. Boutry S, Brunin S, Mahieu I, et al. Magnetic labeling of non-phagocytic adherent cells with iron oxide nanoparticles: a comprehensive study. Contrast Media Mol Imaging. 2008;3:223-232.

21. Talens-Visconti R, Bonora A, Jover R, et al. Hepatogenic differentiation of human mesenchymal stem cells from adipose tissue in comparison with bone marrow mesenchymal stem cells. World $J$ Gastroenterol. 2006;12:5834-5845.

22. Lin CS, Lin G, Lue TF. Allogeneic and xenogeneic transplantation of adipose-derived stem cells in immunocompetent recipients without immunosuppressants. Stem Cells Dev. July 3, 2012. [Epub ahead of print.]

23. Joo HH, Jo HJ, Jung TD, et al. Adipose-derived stem cells on the healing of ischemic colitis: a therapeutic effect by angiogenesis. Int $J$ Colorectal Dis. May 16, 2012. [Epub ahead of print.]

24. Valina C, Pinkernell K, Song YH, et al. Intracoronary administration of autologous adipose tissue-derived stem cells improves left ventricular function, perfusion, and remodelling after acute myocardial infarction. Eur Heart J. 2007;28:2667-2677.

25. di Summa PG, Kingham PJ, Raffoul W, et al. Adipose-derived stem cells enhance peripheral nerve regeneration. J Plast Reconstr Aesthet Surg. 2010;63:1544-1552.
26. Qiu B, Yang X. Molecular MRI of hematopoietic stem-progenitor cells: in vivo monitoring of gene therapy and atherosclerosis. Nat Clin Pract Cardiovasc Med. 2008:5:396-404.

27. Ma ZL, Mai XL, Sun JH, et al. Inhibited atherosclerotic plaque formation by local administration of magnetically labeled endothelial progenitor cells (EPCs) in a rabbit model. Atherosclerosis. 2009;205: 80-86.

28. Hristov M, Zernecke A, Liehn EA, et al. Regulation of endothelial progenitor cell homing after arterial injury. Thromb Haemost. 2007;98: 274-277.

29. Chen R, Yu H, Jia ZY, et al. Efficient nano iron particle-labeling and noninvasive MR imaging of mouse bone marrow-derived endothelial progenitor cells. Int J Nanomedicine. 2011;6:511-519.

30. Kostura L, Kraitchman DL, Mackay AM, et al. Feridex labeling of mesenchymal stem cells inhibits chondrogenesis but not adipogenesis or osteogenesis. NMR Biomed. 2004;17:513-517.

31. Guzman R, Uchida N, Bliss TM, et al. Long-term monitoring of transplanted human neural stem cells in developmental and pathological contexts with MRI. Proc Natl Acad Sci U S A. 2007;104: 10211-10216.

32. Arbab AS, Bashaw LA, Miller BR, et al. Intracytoplasmic tagging of cells with ferumoxides and transfection agent for cellular magnetic resonance imaging after cell transplantation: methods and techniques. Transplantation. 2003;76:1123-1130.

33. Serganova I, Mayer-Kukuck P, Huang R, et al. Molecular imaging reporter gene imaging. Handb Exp Pharmacol. 2008;185:167-223.

34. Yang J, Zhang H, Zhao L, et al. Human adipose tissue-derived stem cells protect impaired cardiomyocytes from hypoxia/reoxygenation injury through hypoxia-induced paracrine mechanism. Cell Biochem Funct. 2012;30:505-514.

35. Zolochevska O, Yu G, Gimble JM, et al. Pigment epithelial-derived factor and melanoma differentiation associated gene-7 cytokine gene therapies delivered by adipose-derived stromal/mesenchymal stem cells are effective in reducing prostate cancer cell growth. Stem Cells Dev. 2012;21:1112-1123.

36. Kim U, Shin DG, Park JS, et al. Homing of adipose-derived stem cells to radiofrequency catheter ablated canine atrium and differentiation into cardiomyocyte-like cells. Int J Cardiol. 2011;146:371-378.

37. Ziadloo A, Burks SR, Gold EM, et al. Enhanced homing permeability and retention of bone marrow stromal cells by noninvasive pulsed focused ultrasound. Stem Cells. 2012;30:1216-1227. 


\section{Supplementary figures}
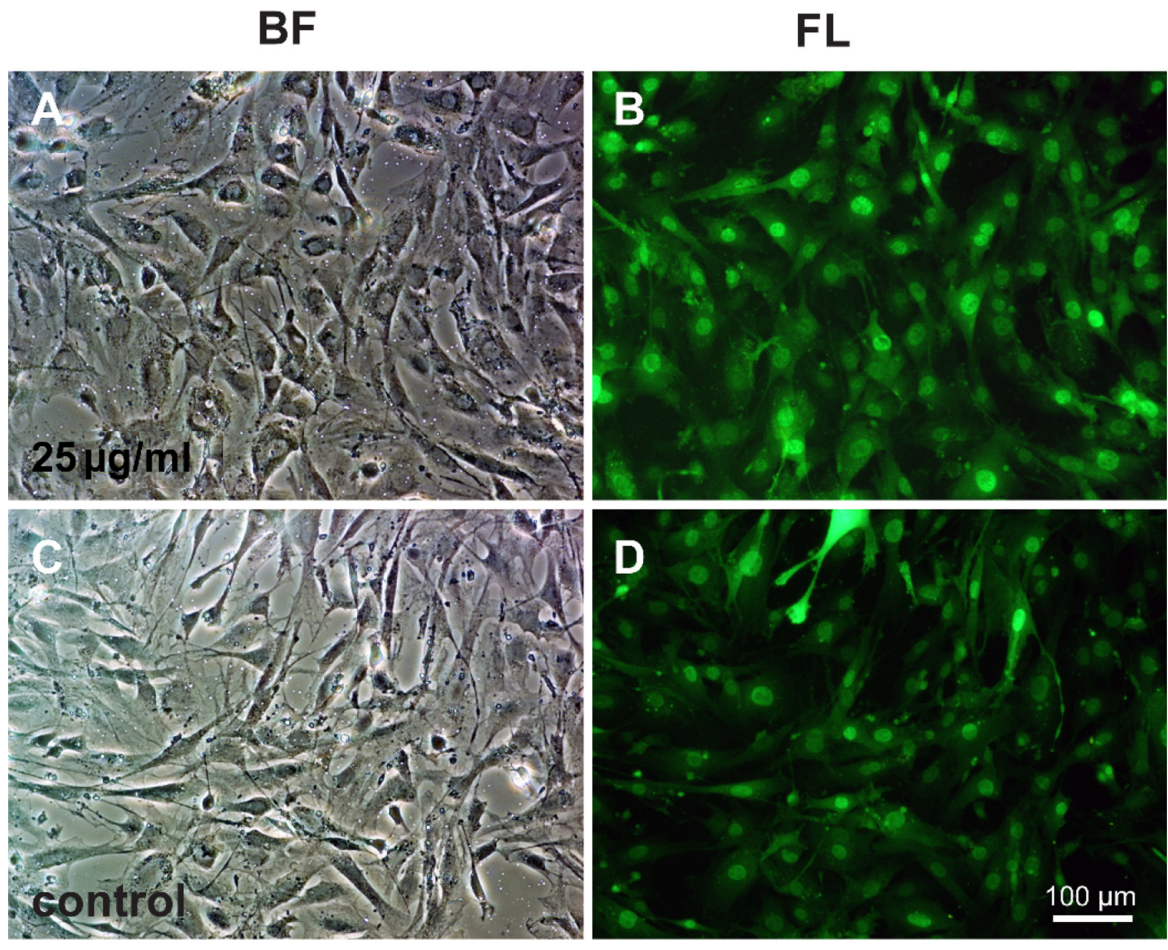

Figure SI Morphology of GFP-ADSCs labeled with $25 \mu \mathrm{g} / \mathrm{mL}$ SPIO.

Notes: (A) Bright field of cells labeled with $25 \mu \mathrm{g} / \mathrm{mL}$ SPIO. (B) Fluorescent microscopy image of the same view of A showed GFP expression of whole labeled cells. (C) Negative control cells without treatment with SPIO. (D) The same view of $C$ was observed under fluorescence microscopy. Scale bar measures I00 $\mu$ m. Abbreviations: GFP-ADSCs, green fluorescent protein-adipose-derived stem cells; BF, bright field; FL, fluorescent light.
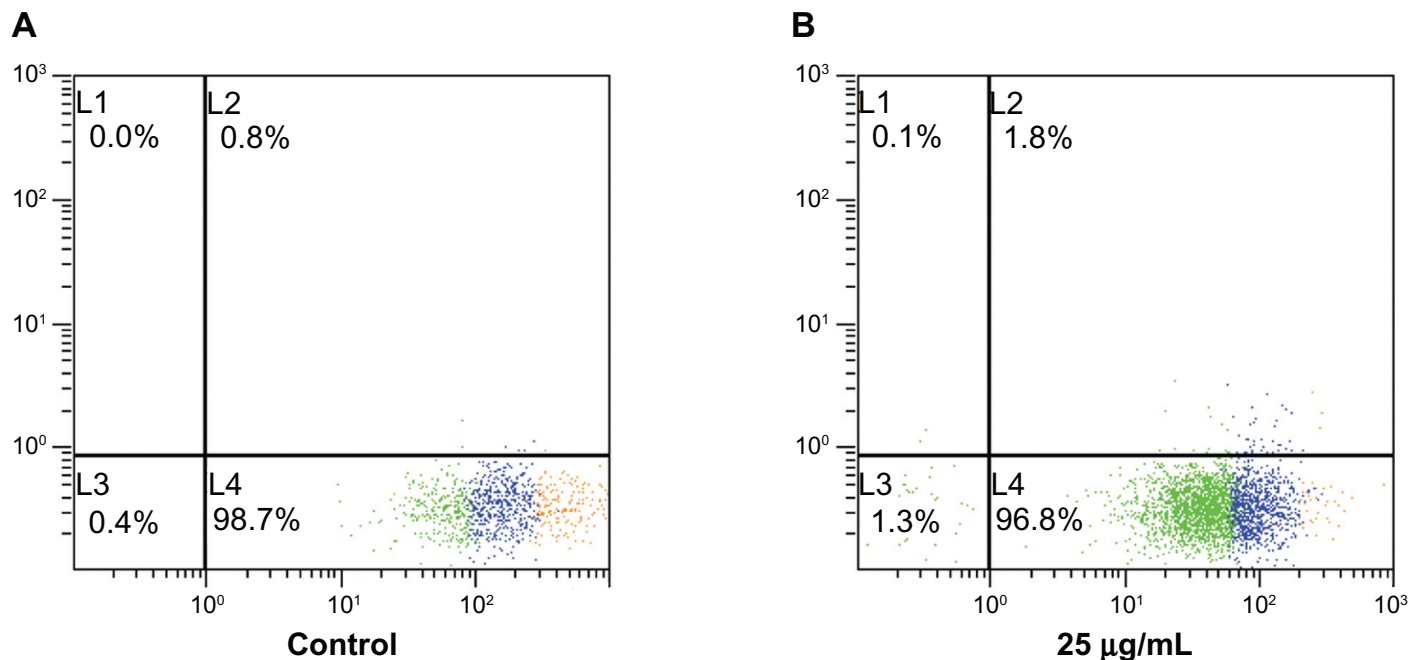

Figure S2 Annexin $V$ staining analysis of apoptosis in GFP-ADSCs labeled with $25 \mu \mathrm{g} / \mathrm{ml}$ SPIO.

Notes: (A) Negative control cells without treatment with SPIO. (B) GFP-ADSCs labeled with $25 \mu \mathrm{g} / \mathrm{mL}$ SPIO.

Abbreviation: GFP-ADSCs, green fluorescent protein adipose-derived stem cells. 
A

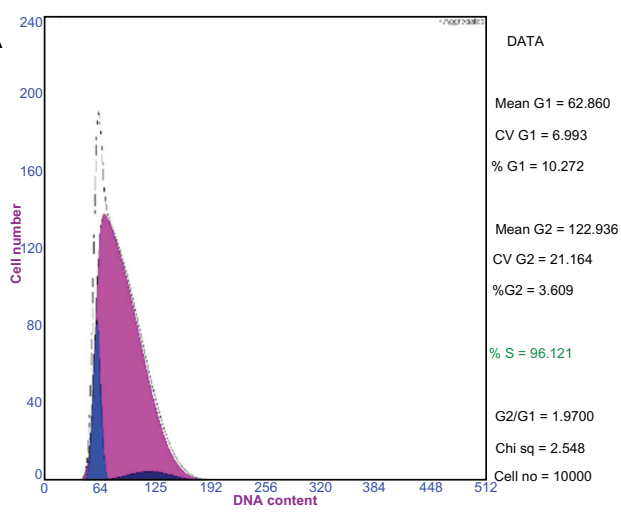

B

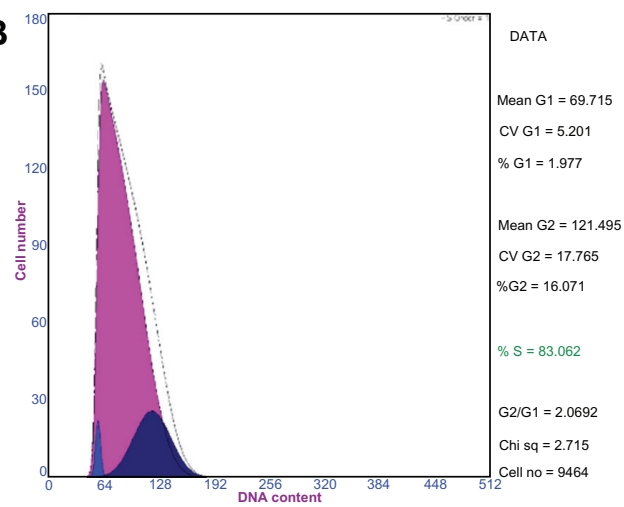

Figure S3 Cell cycle of labeled or unlabeled GFP-ADSCs with $25 \mu \mathrm{g} / \mathrm{ml}$ SPIO.

Notes: FCM showed that about $86.121 \%$ of unlabeled GFP-ADSCs (A) and about $83.052 \%$ of labeled GFP-ADSCs (B) were in proliferative state (S phase). Abbreviations: GFP-ADSCs, green fluorescent protein adipose-derived stem cells; FCM, Flow Cytometry Method.
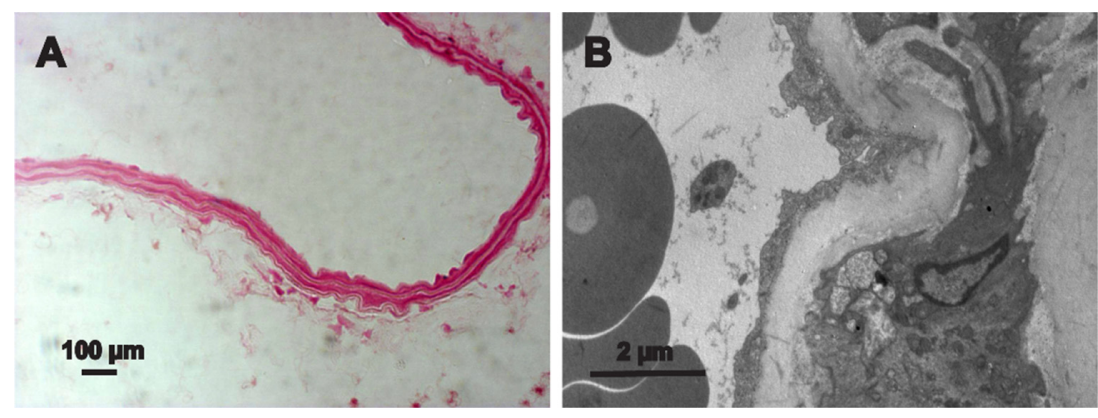

Figure S4 Prussian blue staining, TEM examination of the control groups.

Notes: (A) Prussian blue staining showed no blue-stained iron particles in the lesion area of the control animals. (B) TEM further demonstrated no iron particles accumulated in the lesion area of the control animals. Scale bar A measures $100 \mu \mathrm{m}, \mathrm{B}$ measures $2 \mu \mathrm{m}$.

Abbreviation: TEM, transmission electron microscope.
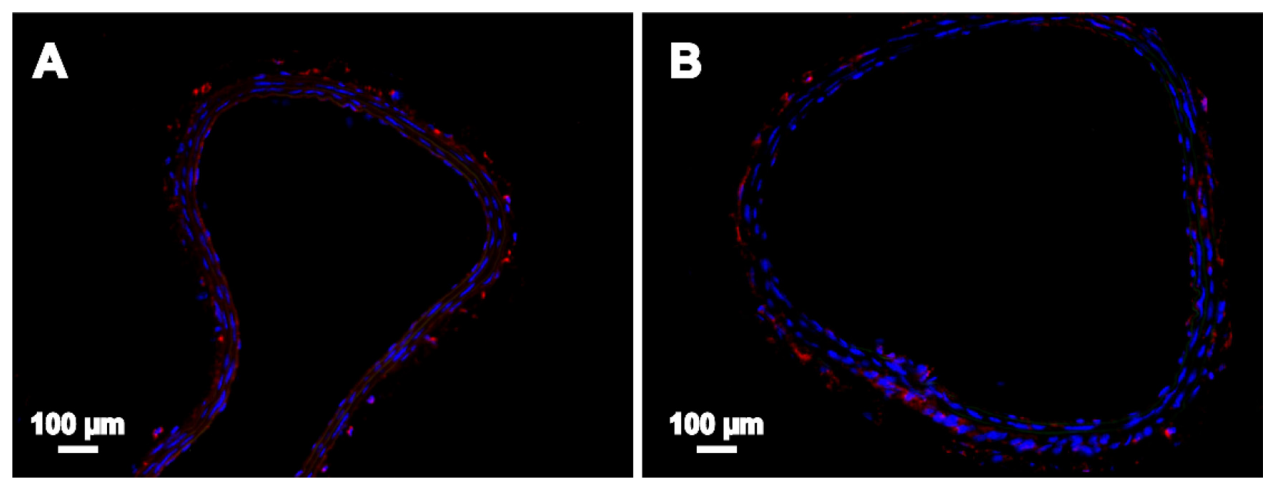

Figure S5 Histological Examination of the injured carotid artery at day 7 and 30 following transplantation.

Notes: (A) Macrophage mark MAC-3 could be detected at $7 \mathrm{~d}$. (B) The number of macrophage was obviously decreasing at $30 \mathrm{~d}$. Scale bar measures I00 $\mu$ m.

International Journal of Nanomedicine

\section{Publish your work in this journal}

The International Journal of Nanomedicine is an international, peerreviewed journal focusing on the application of nanotechnology in diagnostics, therapeutics, and drug delivery systems throughou the biomedical field. This journal is indexed on PubMed Central, MedLine, CAS, SciSearch ${ }^{\circledR}$, Current Contents ${ }^{\circledR} /$ Clinical Medicine,

\section{Dovepress}

Journal Citation Reports/Science Edition, EMBase, Scopus and the Elsevier Bibliographic databases. The manuscript management system is completely online and includes a very quick and fair peer-review system, which is all easy to use. Visit http://www.dovepress.com/ testimonials.php to read real quotes from published authors.

\footnotetext{
Submit your manuscript here: http://www.dovepress.com/international-journal-of-nanomedicine-journal
} 